\title{
Identification of Common Pathogenetic Processes between Schizophrenia and Diabetes Mellitus by Systems Biology Analysis
}

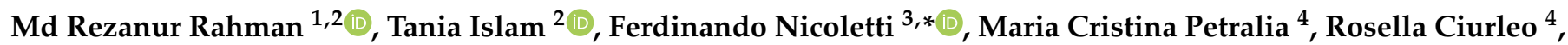 \\ Francesco Fisicaro ${ }^{3}{ }^{-}$, Manuela Pennisi ${ }^{3}$, Alessia Bramanti ${ }^{4}$, Talip Yasir Demirtas ${ }^{5}{ }^{\circledR}$, Esra Gov ${ }^{5}$, \\ Md Rafiqul Islam ${ }^{6,7}$, Bashair M. Mussa ${ }^{8}\left[\right.$, Mohammad Ali Moni ${ }^{9}{ }^{\circledR}$ and Paolo Fagone ${ }^{3}(\mathbb{C}$
}

1 Department of Biotechnology and Genetic Engineering, Faculty of Biological Sciences, Islamic University, Kushtia 7003, Bangladesh; rezanur12@yahoo.com

2 Department of Biochemistry and Biotechnology, Khwaja Yunus Ali University, Enayetpur, Sirajganj 6751, Bangladesh; taniaislam1304@gmail.com

3 Department of Biomedical and Biotechnological Sciences, University of Catania, 95124 Catania, Italy; drfrancescofisicaro@gmail.com (F.F.); Manuela.pennisi@unict.it (M.P.); paolofagone@yahoo.it (P.F.)

4 IRCCS Centro Neurolesi “Bonino-Pulejo”, Via Provinciale Palermo, Contrada Casazza, 98124 Messina, Italy; m.cristinapetralia@gmail.com (M.C.P.); rossella.ciurleo@irccsme.it (R.C.); alessia.bramanti@irccsme.it (A.B.)

5 Department of Bioengineering, Faculty of Engineering, Adana Alparslan Turkes Science and Technology University, Adana 01250, Turkey; tyasird@gmail.com (T.Y.D.); egov@atu.edu.tr (E.G.)

6 School of Biomedical Sciences, Faculty of Health, Institute of Health and Biomedical Innovation, Queensland University of Technology (QUT), Brisbane, QLD 4059, Australia; rafiqulislambd7@gmail.com

7 Department of Pharmacy, Faculty of Biological Science and Technology, Jashore University of Science and Technology, Jashore 7408, Bangladesh

check for

updates

Citation: Rahman, M.R.; Islam, T.; Nicoletti, F.; Petralia, M.C.; Ciurleo, R.; Fisicaro, F.; Pennisi, M.; Bramanti, A.; Demirtas, T.Y.; Gov, E.; et al. Identification of Common Pathogenetic Processes between Schizophrenia and Diabetes Mellitus by Systems Biology Analysis. Genes 2021, 12, 237. https://doi.org/ 10.3390/genes12020237

Received: 2 December 2020

Accepted: 4 February 2021

Published: 7 February 2021

Publisher's Note: MDPI stays neutral with regard to jurisdictional claims in published maps and institutional affiliations.

Copyright: () 2021 by the authors. Licensee MDPI, Basel, Switzerland. This article is an open access article distributed under the terms and conditions of the Creative Commons Attribution (CC BY) license (https:// creativecommons.org/licenses/by/ $4.0 /)$.
8 Basic Medical Sciences Department, College of Medicine, University of Sharjah, Sharjah P.O. Box 27272, United Arab Emirates; bmussa@sharjah.ac.ae

9 WHO Collaborating Centre on eHealth, UNSW Digital Health, School of Public Health and Community Medicine, Faculty of Medicine, Sydney, NSW 2052, Australia; m.moni@unsw.edu.au

* Correspondence: ferdinic@unict.it

Abstract: Schizophrenia (SCZ) is a psychiatric disorder characterized by both positive symptoms (i.e., psychosis) and negative symptoms (such as apathy, anhedonia, and poverty of speech). Epidemiological data show a high likelihood of early onset of type 2 diabetes mellitus (T2DM) in SCZ patients. However, the molecular processes that could explain the epidemiological association between SCZ and T2DM have not yet been characterized. Therefore, in the present study, we aimed to identify underlying common molecular pathogenetic processes and pathways between SCZ and T2DM. To this aim, we analyzed peripheral blood mononuclear cell (PBMC) transcriptomic data from SCZ and T2DM patients, and we detected 28 differentially expressed genes (DEGs) commonly modulated between SCZ and T2DM. Inflammatory-associated processes and membrane trafficking pathways as common biological processes were found to be in common between SCZ and T2DM. Analysis of the putative transcription factors involved in the regulation of the DEGs revealed that STAT1 (Signal Transducer and Activator of Transcription 1), RELA (v-rel reticuloendotheliosis viral oncogene homolog A (avian)), NFKB1 (Nuclear Factor Kappa B Subunit 1), and ERG (ETS-related gene) are involved in the expression of common DEGs in SCZ and T2DM. In conclusion, we provide core molecular signatures and pathways that are shared between SCZ and T2DM, which may contribute to the epidemiological association between them.

Keywords: schizophrenia; type 2 diabetes mellitus; differentially expressed genes; pathways; transcription factors

\section{Introduction}

Schizophrenia (SCZ) is a psychiatric disorder characterized by psychotic events in a continuous and/or relapsing mode. Compared to the general population, SCZ patients 
are reported with a 1.5-2 times higher risk of type 2 diabetes (T2DM) [1]. Several factors, including the environment, the use of antipsychotic medications, and genetic predisposition, may explain this epidemiological association [1-4]. People with serious psychiatric disorders live sedentary lives and smoke more often than the general population, which are considered as risk factors of T2DM [4]. Antipsychotic medicines are also found to trigger metabolic adversity that leads to a dramatic increase in body weight [5]. Multiple reports have demonstrated a link between antipsychotic medications and the likelihood of developing T2DM [6-8], but this still needs further confirmation [4]. Multiple etiopathogenetic mechanisms seem to be involved in the association between SCZ and T2DM. The genetic contribution of SCZ in the early onset of T2DM has been investigated and several genes were identified by genome-wide association studies [9-12]. Although genetic predispositions are recognized, it is believed that environmental, neurological, and metabolic processes may contribute to the increased risk of developing T2DM by SCZ patients. However, the pathogenetic mechanisms of nongenetic variants of SCZ and T2DM still need to be explored.

Alterations of the transcriptome have lately been explored to characterize the molecular and cellular processes in complex diseases [13,14]. Significant numbers of studies have independently characterized the gene expression signatures of SCZ [15-17] and T2DM $[18,19]$, but no attempt has been made to establish shared gene signatures, associated regulators, and biological processes between SCZ and T2DM. Therefore, the molecular signatures and pathways associated with an increased T2DM risk in SCZ remain unclear. In this study, we integrated peripheral blood mononuclear cell (PBMC) transcriptomic meta-analysis data and systems biology to investigate SCZ and T2DM molecular interactions and pathways that may offer new insights into the shared pathogenetic mechanisms of SCZ and T2DM. The phenotypic and functional analysis of PBMCs has widely been used as a tool to study the etiopathogenetic mechanisms underlying several disorders, including SCZ and diabetes [20,21]. In particular, the transcriptomic analyses of these cells may allow the identification of commonly altered DEG in these two diseases, thus allowing the initial identification of cellular and molecular pathways that are abnormally expressed in SCZ and diabetes. This could allow the identification of specific cellular or soluble biomarkers that may be useful to predict therapeutic responses and help to design tailored therapeutic approaches.

In order to shed light on the possible shared pathways of SCZ and T2DM pathogenesis, functional annotation and transcription factor (TF) analysis was conducted in the present study (Figure 1). 
- Dataset selection from Gene Expression Omnibus.

- Schizophrenia (SCZ) PBMCs gene expression datasets: GSE18312 and GSE27383.

- Type 2 diabetes mellitus (T2DM) PBMCs gene expression dataset: GSE9006.

- Meta-analysis of SCZ datasets (GSE18312 and GSE27383) was done using the ImaGEO web-utility using effect size method.

- T2DM (GSE9006) dataset was preprocessed and analyzed in NetworkAnalyst web-utility, using LIMMA.

- Differentially expressed genes (DEGs) were selected on the basis of false discovery rate $(F D R)<0.1$.

- Identification of common DEGs between SCZ and T2DM was performed by Venn analysis.

- Network analysis was perfomed using Cytoscape.

- Identification of common Gene Ontology terms and enriched molecular pathways was perfomed using Metascape software.

- Identification of enriched transcription factors via Metascape software.

Figure 1. The workflow used in this study.

\section{Materials and Methods}

\subsection{Acquisition of Blood Transcriptomic Data}

In order to obtain suitable datasets of SCZ and T2DM, we queried the transcriptomics database Gene Expression Omnibus (GEO). We searched the database using the following keywords: "schizophrenia", "blood", and "Homo sapiens". Inclusion criteria for the selection of the datasets were as follows: (i) whole-genome gene expression data; (ii) the datasets should contain both cases and matched controls; (iii) human peripheral blood mononuclear cell samples. For SCZ, we found the two datasets, GSE18312 [22,23] and GSE27383 [24]. GSE18312 contained peripheral blood mononuclear cell (PBMC) gene expression (messenger RNAs (mRNAs)) of 13 SCZ cases and eight healthy controls. GSE27383 contained gene expression profiling of PBMC samples from 43 SCZ cases and 29 controls. Similarly, we queried the GEO database with the above search criteria for T2DM datasets, and the only available dataset was GSE9006 [20], which contained gene expression profiling of 12 T2DM cases and 24 controls from PBMCs samples. The characteristics of the datasets are presented in Table 1.

\subsection{Analysis of Transcriptomic Data}

We performed a meta-analysis of the two SCZ PBMC datasets (GSE18312 and GSE27383) using the effect size method via ImaGEO web-utility [25] as described elsewhere [26]. From the meta-analysis, we selected the differentially expressed genes (DEGs) in SCZ PBMCs compared to controls. GSE9006 was analyzed to identify DEGs using the LIMMA method in R [27] as implemented in NetworkAnalyst [28]. For the normalization of the dataset, we employed the variance stabilizing normalization (VSN) algorithm [29], followed by quan- 
tile normalization [30]. The significant genes were selected on the basis of a false discovery rate $(\mathrm{FDR})<0.1$. The adjustment of the $p$-value was done by the Benjamini-Hochberg method. The total number of shared genes among the datasets was 11,112, which were considered for all the analyses.

Table 1. Characteristics of the datasets used in this study.

\begin{tabular}{|c|c|c|c|c|c|}
\hline Accession & Source/Tissue & Sample & Patients Characteristics & Healthy Controls Characteristics & Platform \\
\hline \multicolumn{6}{|c|}{ Schizophrenia } \\
\hline \multirow[b]{3}{*}{ GSE18312 } & \multirow[b]{3}{*}{ PBMCs } & \multirow[b]{3}{*}{$\begin{array}{l}13 \text { SCZ patients } \\
\text { and } 8 \text { healthy } \\
\text { controls }\end{array}$} & Age (years): $43.6 \pm 8.6$ & Age (years): $44.6 \pm 6.5$ & \multirow[b]{3}{*}{$\begin{array}{l}\text { Affymetrix Human } \\
\text { Exon 1.0 ST Array }\end{array}$} \\
\hline & & & $\%$ female: 30.7 & $\%$ female: 37.5 & \\
\hline & & & $\begin{array}{c}\text { Race: } \\
\text { European-American 38.4\% } \\
\text { Hispanic } 15.3 \% \\
\text { African-American } 46.2 \%\end{array}$ & $\begin{array}{c}\text { Race: } \\
\text { European-American } 65.5 \% \\
\text { Hispanic } 12.5 \% \\
\text { Asian } 12.5 \% \\
\text { African-American } 12.5 \%\end{array}$ & \\
\hline \multirow[b]{2}{*}{ GSE27383 } & \multirow[b]{2}{*}{ PBMCs } & \multirow[b]{2}{*}{$\begin{array}{l}43 \mathrm{SCZ} \text { subjects } \\
\text { and } 29 \text { controls }\end{array}$} & Age (years): $23 \pm 4$ & Age (years): $23.9 \pm 4.1$ & \multirow[b]{2}{*}{$\begin{array}{c}\text { Affymetrix Human } \\
\text { Genome U133 Plus } 2.0 \\
\text { Array }\end{array}$} \\
\hline & & & $\begin{array}{c}\text { Race: } \\
\text { European } 48.8 \% \\
\text { Surinamese/African } 14.6 \% \\
\text { Cape Verdean } 2.4 \% \\
\text { Surinamese/Hindustani } 14.6 \% \\
\text { Moroccan/North African } 4.9 \% \\
\text { Asian } 2.4 \% \\
\text { Mixed } 7.3 \% \\
\text { Unknown } 4.9 \%\end{array}$ & $\begin{array}{c}\text { Race: } \\
\text { European } 82.6 \% \\
\text { Surinamese/African 3.4\% } \\
\text { Surinamese/Hindustani 3.4\% } \\
\text { Asian 3.4\% } \\
\text { Mixed } 6.9 \%\end{array}$ & \\
\hline \multicolumn{6}{|c|}{ Type 2 diabetes mellitus } \\
\hline \multirow[b]{3}{*}{ GSE9006 } & \multirow[b]{3}{*}{ PBMCs } & \multirow[b]{3}{*}{$\begin{array}{l}12 \mathrm{~T} 2 \mathrm{DM} \\
\text { patients and } 24 \\
\text { healthy controls }\end{array}$} & Age (years): $14 \pm 2.3$ & Age (years): $11.3 \pm 4.6$ & \multirow[b]{3}{*}{$\begin{array}{l}\text { Affymetrix Human } \\
\text { Genome U133A Array }\end{array}$} \\
\hline & & & $\%$ female: 58 & $\%$ female: 58 & \\
\hline & & & $\begin{array}{c}\text { Race: } \\
\text { Caucasian } 16.6 \% \\
\text { Hispanic } 16.6 \% \\
\text { African-American } 58.3 \% \\
\text { Asian } 8.3 \%\end{array}$ & $\begin{array}{c}\text { Race: } \\
\text { Caucasian } 45.8 \% \\
\text { Hispanic } 29.1 \% \\
\text { Mixed or unknown } 25 \%\end{array}$ & \\
\hline
\end{tabular}

PBMC: peripheral blood mononuclear cell; SCZ: Schizophrenia; T2DM: type 2 diabetes mellitus.

To evaluate the significance of the overlap between the DEGs belonging to the SCZ and T2DM signatures, a one-tailed chi-square test was performed, using the total number of shared genes among the datasets as the background [31]. The representation factor is defined as the number of overlapping genes divided by the expected number of overlapping genes drawn from the two groups. A representation factor $>1$ indicates more overlap than expected, while a representation factor $<1$ indicates less overlap than expected. A $p$-value $<0.05$ was considered to be statistically significant.

\subsection{Functional Insights into the Significant Genes}

For the gene ontology and enrichment analysis, we utilized the bioinformatics tool "Metascape" [32]. By default, the enrichment analysis performed by Metascape makes use of data sources, including gene ontology, KEGG (Kyoto Encyclopedia of Genes and Genomes), and Reactome. Metascape clusters enriched terms into nonredundant groups. In each cluster, Metascape selects the most important (lowest $p$-value) term to represent the cluster in the bar graph. The hypergeometric test was performed to screen significant terms. A Bonferroni corrected $p$-value $<0.05$ was considered for significant term selection.

\subsection{Network Analysis}

The GeneMania database [33] was used to construct a network of the common DEGs between SCZ and T2DM. Interaction data included physical interaction, co-expression, prediction, co-localization, pathway, genetic interactions, and shared protein domains. GeneMania assigns weights in order to maximize the connectivity between all input genes. A maximum of 20 resultant genes and a maximum of 10 attributes are considered, by default [33]. The Cytoscape software [34] was used for visualization of the network and to perform network analysis, using the NetworkAnalyzer utility. Topological analysis was 
performed considering the network as undirected (i.e., containing only undirected edges). Hubs were defined as the top $20 \%$ of nodes with the highest degree of centrality, which corresponds to the number of edges linked to each given node.

\section{Results}

\subsection{Identification of Common Transcriptional Signatures between SCZ and T2DM PBMCS}

First of all, we performed a transcriptomic meta-analysis of two SCZ PBMCs datasets (with accession numbers GSE18312 and GSE27383) obtained from the GEO database. The meta-analysis identified 354 significant DEGs at FDR $<0.1$. The complete list of DEGs is presented in Table S1 (Supplementary Materials). Secondly, we analyzed the PBMC transcriptomic dataset of T2DM (with accession number GSE9006). The analysis revealed 678 significant DEGs between T2DM and healthy controls (FDR $<0.1$ ). The complete list of DEGs characterizing T2DM PBMCs is presented in Table S2 (Supplementary Materials).

Our analysis showed a significant number of overlapping DEGs between SCZ and T2DM PBMCs (Table 2). In particular, we found seven common upregulated DEGs ( $p=0.01$ using a one-tailed chi-square test; representation factor $=2.9)(B T G 2, E E D, H B P 1, P T G S 2$, NAMPT, ATP6V0A1, and EAF2) between SCZ and T2DM. Our analysis also showed that 21 downregulated DEGs (LONP1, RALY, PACS2, SH2D2A, DGKZ, MEPCE, KCTD13, ELF4, MFSD10, MAZ, SIGIRR, FCHO1, BCR, PPRC1, TPM2, IDUA, PFN1, LMF2, FLNA, APRT, and SLC10A3) were common between SCZ and T2DM ( $p<0.0001$ using a one-tailed chisquare test; representation factor $=2.5$ ) (Figure 2). On the other hand, two genes were found to be upregulated in SCZ and downregulated in T2DM ( $p=0.394$ using a one-tailed chi-square test; representation factor $=0.9)(T E C R$ and $H N R N P K)$, while four genes were found to be downregulated in SCZ and upregulated in T2DM ( $p=0.061$ using a one-tailed chi-square test; representation factor $=0.5)(R I C 8 B, C S R N P 2, A S T E 1$, and SLA $)$.

Table 2. Differentially expressed genes concordantly regulated in SCZ and T2DM PBMCs.

\begin{tabular}{|c|c|c|}
\hline Genes Symbol & Description & Regulation \\
\hline BTG2 & BTG anti-proliferation factor 2 & Upregulated \\
\hline EED & embryonic ectoderm development & Upregulated \\
\hline$H B P 1$ & HMG-box transcription factor 1 & Upregulated \\
\hline PTGS2 & prostaglandin-endoperoxide synthase 2 & Upregulated \\
\hline NAMPT & nicotinamide phosphoribosyltransferase & Upregulated \\
\hline ATP6V0A1 & ATPase $\mathrm{H}+$ transporting V0 subunit a1 & Upregulated \\
\hline$E A F 2$ & ELL associated factor 2 & Upregulated \\
\hline LONP1 & lon peptidase 1 , mitochondrial & Downregulated \\
\hline RALY & RALY heterogeneous nuclear ribonucleoprotein & Downregulated \\
\hline PACS2 & phosphofurin acidic cluster sorting protein 2 & Downregulated \\
\hline$S H 2 D 2 A$ & $\mathrm{SH} 2$ domain containing $2 \mathrm{~A}$ & Downregulated \\
\hline$D G K Z$ & diacylglycerol kinase zeta & Downregulated \\
\hline$M E P C E$ & methylphosphate capping enzyme & Downregulated \\
\hline KCTD13 & potassium channel tetramerization domain containing 13 & Downregulated \\
\hline ELF4 & E74 like ETS transcription factor 4 & Downregulated \\
\hline MFSD10 & major facilitator superfamily domain containing 10 & Downregulated \\
\hline$M A Z$ & MYC associated zinc finger protein & Downregulated \\
\hline SIGIRR & single Ig and TIR domain containing & Downregulated \\
\hline FCHO1 & FCH domain only 1 & Downregulated \\
\hline$B C R$ & BCR, RhoGEF and GTPase activating protein & Downregulated \\
\hline PPRC1 & $\begin{array}{l}\text { peroxisome proliferator-activated receptor } \gamma, \\
\text { coactivator-related } 1\end{array}$ & Downregulated \\
\hline TPM2 & tropomyosin 2 & Downregulated \\
\hline IDUA & iduronidase, $\alpha$-L- & Downregulated \\
\hline PFN1 & profilin 1 & Downregulated \\
\hline$L M F 2$ & lipase maturation factor 2 & Downregulated \\
\hline FLNA & filamin A & Downregulated \\
\hline$A P R T$ & adenine phosphoribosyltransferase & Downregulated \\
\hline SLC10A3 & solute carrier family 10 member 3 & Downregulated \\
\hline
\end{tabular}


A

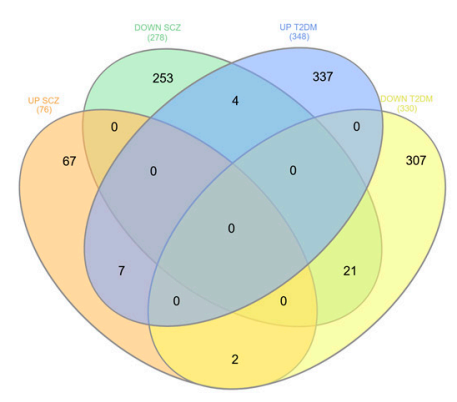

B

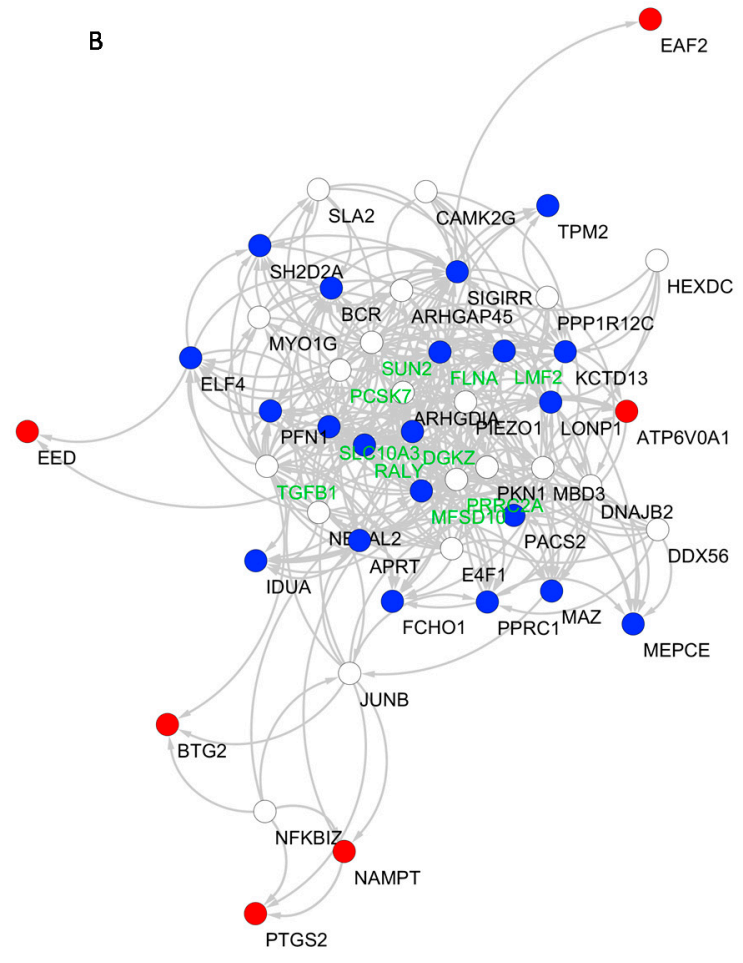

Figure 2. The common differentially expressed genes and pathways between schizophrenia (SCZ) and type 2 diabetes mellitus (T2DM). (A) Venn diagram representing common differentially expressed genes (DEGs) between SCZ and T2DM, where up denotes upregulated and down denotes downregulated DEGs. (B) A functional network was constructed using the 28 common DEGs between SCZ and T2DM, using the GeneMania prediction server. Overall, the network included 47 nodes. Nodes colored in red represent the commonly upregulated DEGs, while nodes in blue represent the commonly downregulated DEGs between SCZ and T2DM. Nodes labeled in green represent the hub genes of the network.

Network analysis was performed on the 28 commonly regulated DEGs between SCZ and T2DM. According to the functional similarity and shared properties, 19 genes were predicted to interact with the initial 28 DEGs and are presented in the functional association network in Figure 2B. Network analysis identified 10 hub genes, i.e., FLNA, PRRC2A, MFSD10, RALY, TGFB1, LMF2, PCSK7, SUN2, DGKZ, and ARHGDIA.

\subsection{Identification of Common Functional Gene Ontology Terms in SCZ and T2DM PBMCs}

To shed light on the biological insights of DEGs, we carried out functional enrichment analysis to identify gene ontologies and molecular pathways enriched by the common DEGs. Several gene ontology terms were found in common between SCZ and T2DM (Figure 3). Among the most significant terms enriched by the upregulated DEGs, which 
were in common between SCZ and T2DM, we found "positive regulation of catabolic process", "regulation of binding", "membrane trafficking", "adaptive immune systems", and "apoptotic signaling pathway" (Figure 3B).

A
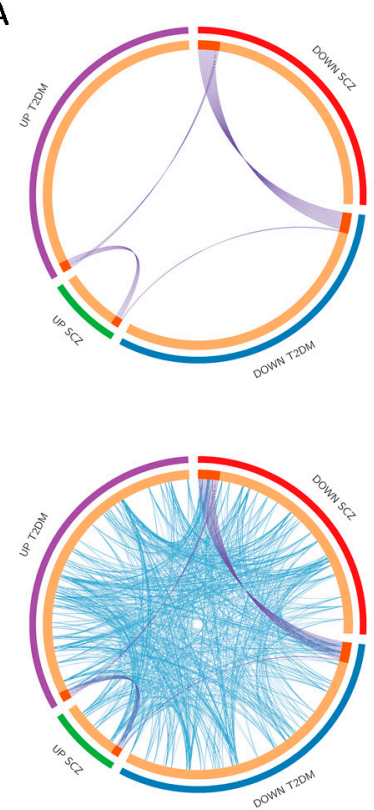

B

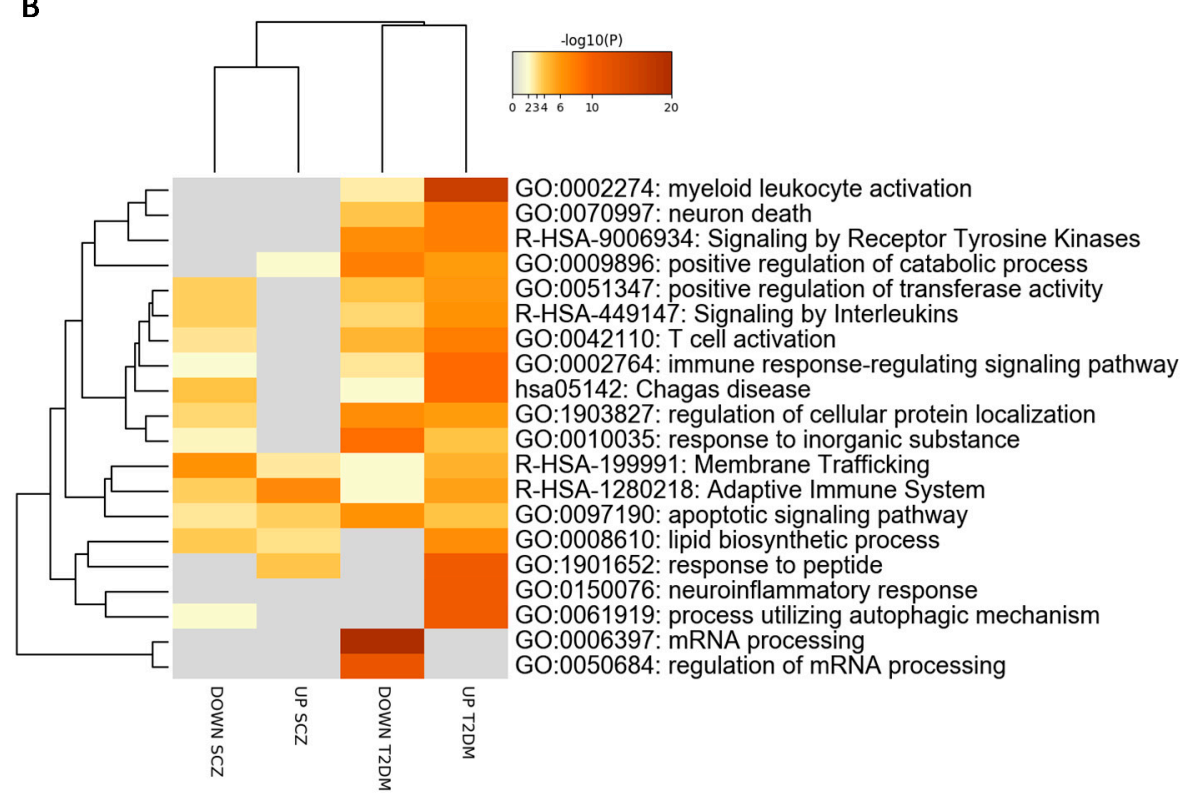

Figure 3. Functional annotations performed on the differentially expressed genes in schizophrenia (SCZ) and type 2 diabetes mellitus (T2DM) peripheral blood mononuclear cells (PBMCs). (A) Circos plot showing overlapping between the differentially expressed genes (DEGs) in SCZ and T2DM PBMCs. Purple lines link the same genes that are shared by the input lists. Blue lines link the different genes that fall in the same ontology term. (B) Hierarchical clustering of the top 20 most enriched terms among the DEGs in SCZ and T2DM PBMCs. The heatmap is colored by the $p$-values, and gray cells indicate the lack of significant enrichment.

On the other hand, among gene terms enriched by the downregulated DEGs in SCZ and T2DM, we found "lymphocyte activation", "signaling by interleukins", "regulation of cellular protein localization", "positive regulation of transferase activity", "asparagine $N$-linked glycosylation", "membrane trafficking", "adaptive immune systems", and "apoptotic signaling pathway" (Figure 3B). It is interesting to note that "membrane trafficking", "adaptive immune systems", and "apoptotic signaling pathway" were common in both upregulated and downregulated DEGs between SCZ and T2DM (Figure 3B and Figure S1, Supplementary Materials).

\subsection{Prediction of Transcription Factor Overlapping between SCZ and T2DM PBMCs}

Analysis of the putative transcription factors involved in the regulation of the DEGs modulated in SCZ and T2DM revealed that STAT1, RELA, and NFKB1 are involved in the expression of common upregulated genes in SCZ, and T2DM. ERG was detected as regulator of the common downregulated genes in SCZ and T2DM (Figure 4; Table S3, Supplementary Materials). 


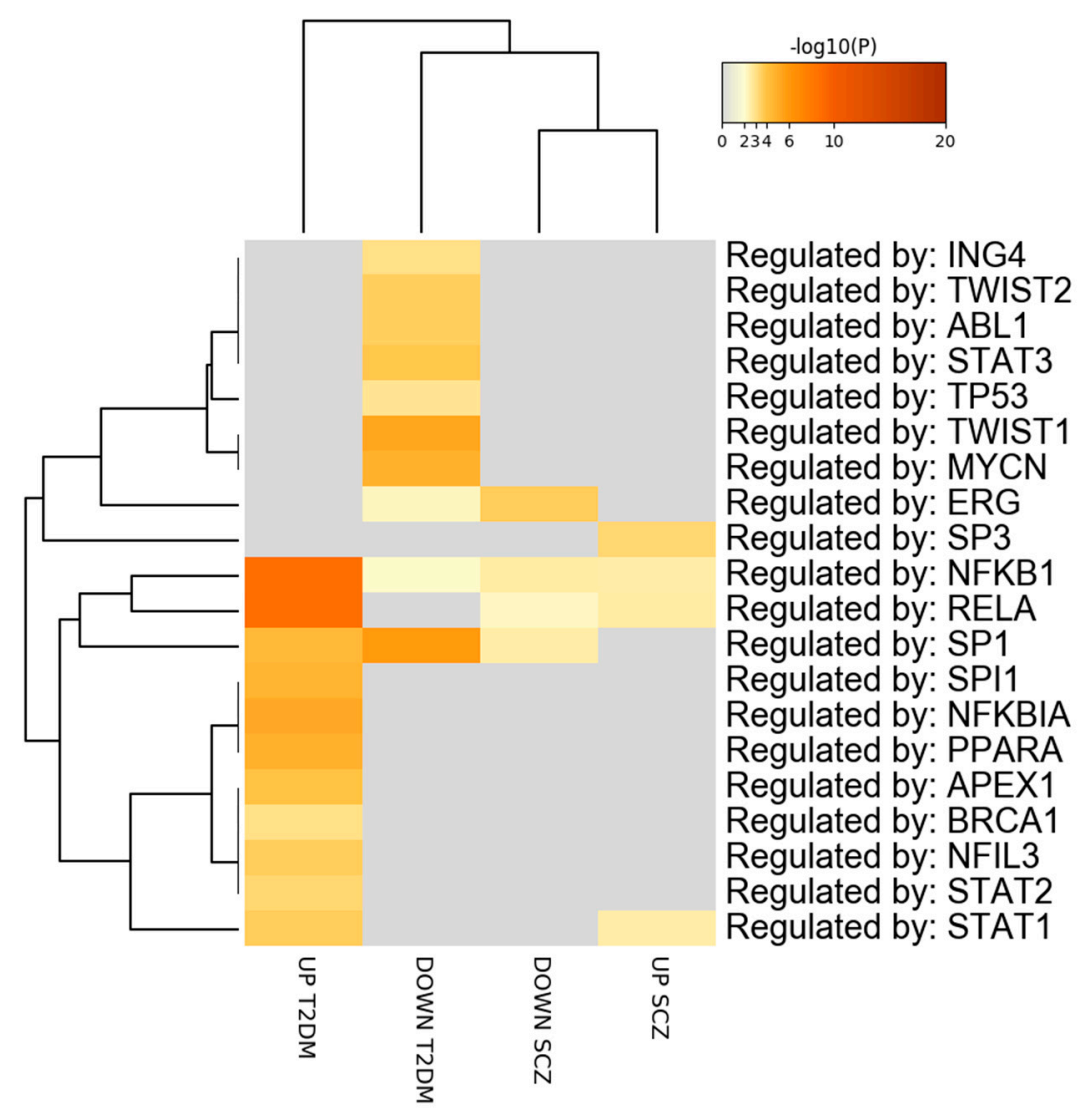

Figure 4. Putative transcription factors regulating the differentially expressed genes in peripheral blood mononuclear cells (PBMCs) from schizophrenia (SCZ) and type 2 diabetes mellitus (T2DM). The transcription factors are visualized as a hierarchical clustering. The heatmap is colored by the $p$-values, and gray cells indicate the lack of significant enrichment.

\section{Discussion}

Despite the effort of genome-wide association studies to detect the genetic contribution of SCZ in T2DM, the molecular mechanisms of T2DM comorbidity in a subset of SCZ patients remains to be deciphered [9-12]. Hackinger et al. identified 29 genes that were associated with both T2DM and SCZ, using a genome-wide association approach [9]. Purcell and coworkers performed SCZ risk analysis, but did not find any significant correlation [10]. Another study also investigated the genetic risk of SCZ and detected a weak link between risk of SCZ score and T2DM [11]. It should be noted that none of the previously described genes were found to be modulated in our analysis. The use of whole-genome transcriptomic analyses has largely been used in the past few years to study autoimmune disorders, cancer, and neurodegenerative and neuropsychiatric diseases [17,35-38], in order to shed light on their pathogenetic mechanisms [39-41] and to identify potential therapeutic targets [42-45]. In the present study, we showed a common transcriptomic signature between $\mathrm{SCZ}$ and T2DM, suggesting potential overlapping pathogenetic processes. A number of genes that were found to overlap between SCZ and T2DM have already been associated with either one of these two disorders, particularly DGKZ, APRT, KCTD13, and PTGS2 for SCZ and RALY, FLNA, NAMPT, PTGS2, BCR, APRT, and DGKZ for T2DM, as reported in the DisGeNET database (https: / / www.disgenet.org/ on 10 January 2021). Interestingly, DGKZ, APRT, and PTGS2 are commonly associated with both diseases. The common upregulated DEGs were enriched in the "positive regulation of catabolic process" pathway, which is implicated in the T2DM and low-grade inflammation as manifested by the insulin resistance mechanism observed in T2DM patients [46]. Insulin resistance inhibits the uptake of glucose by adipocytes and muscle cells and prevents glucose synthesis in hepatic cells, suggesting a prominent feature of catabolic processes in T2DM. Our 
analysis also showed the enrichment of "membrane trafficking" as a shared process in both SCZ and T2DM. Membrane trafficking is a process ubiquitously found in all types of tissues, and perturbation of membrane trafficking is involved in various disorders including T2DM, neuropsychiatric, immunological, systemic, and multisystem disorders [47]. Emerging data indicate that clathrin-mediated endocytosis, a key mechanism of the cellular membrane and protein-trafficking systems, may be involved in psychosis, SCZ, and bipolar disorder [48]. Previous studies have also shown that several crucial genes of SCZ are involved in cellular processes linked to cellular and membrane trafficking systems, and that these trafficking systems affect synaptic dysfunction [48]. Indeed, compelling evidence has suggested synaptic dysfunction as causative for several neuropsychiatric disorders [49]. It is hypothesized that dysregulated synaptic development and plasticity are involved in the pathogenesis of SCZ and autism spectrum disorder [49]. Many antipsychotic drugs can affect the proteins of clathrin-mediated trafficking processes, suggesting the possibility to design drugs that may influence membrane trafficking in SCZ and T2DM.

In agreement with previous reports, our study identified that pathways related to the immune system are involved in both SCZ and T2DM [50,51]. Our study identified the "signaling by interleukins" pathway to be enriched, which is notably involved in insulin resistance in T2DM and in SCZ [52]. The impact of the immune system in SCZ pathology is suggested by the epidemiological observation of the increased risk of SCZ patients to develop immune-mediated disorders. Genetic associations have been reported between SCZ and Crohn's disease, ulcerative colitis, multiple sclerosis, psoriasis, and systemic lupus erythematosus [53]. More specifically, Pouget et al. identified 581 variants (563 non-HLA variants and 18 HLA variants) that were associated with immune-mediated disorders at genome-wide significance [53]. In T2DM, a large body of data has also pointed out the role for cytokines in promoting local and systemic inflammation, which may, therefore, represent critical players in the development and maintenance of insulin resistance [54]. In particular, the IL-1 (Interleukin-1) family of cytokines has been linked to obesity-induced adipose tissue inflammation and T2DM. High plasma IL-1 $\beta$ levels have been associated with an increased risk of developing T2DM [55], and mice lacking the inflammasome, IL-1 $\beta$, and receptor IL-1R1 are protected from the development of T2DM [56]. Accordingly, a multicenter, open-label, randomized controlled trial investigating the effects of the IL-1 inhibitor Anakinra in T2DM patients showed a significant reduction in the $\mathrm{HbA1c}$ (glycated hemoglobin A1c) \%, after correcting for clinical confounders, such as sex, age, disease duration, use of oral antidiabetic drug, and body mass index [57]. Moreover, an involvement of the apoptotic signaling pathway was identified in the present study. Interestingly, an activated complement system and caspase-independent apoptosis were found in leukocytes from SCZ patients, supporting a link between SCZ and immune dysregulation and suggesting the presence of apoptotic processes in leukocytes [58]. Along the same lines, expressions of proapoptotic markers (i.e., Caspase-3, Fas, and Bax-BCL2 Associated $\mathrm{X}$ ) were significantly higher, while reduced expression of the antiapoptotic marker Bcl-2 (B-cell lymphoma 2) was observed in lymphocytes of T2DM patients [59].

Next, we analyzed the putative TFs that may regulate the expression (i.e., transcription) of common DEGs in PBMCs from SCZ and T2DM patients. Among the identified TFs, RELA and NFKB1 were enriched for the upregulated DEGs of both SCZ and T2DM. It is generally assumed that aberrant immune and inflammatory responses are involved in SCZ and T2DM. Nuclear factor kappa B (NF-kB) has a very crucial role in immune and inflammatory processes, and RELA encodes a major component of the NF- $\mathrm{kB}$ complex. A previous report showed that three SNPs (rs11820062, rs2306365, and rs7119750) in RELA gene are associated with SCZ [60]. NFKB1 is a component of the NF-kB family. Previous findings also reported a close association between cytokine expression and NF- $\mathrm{KB}$ activation in SCZ [61], which suggests that changes in cytokines expression and the NF- $\mathrm{kB}$ mediated cascade might contribute to the pathogenesis of SCZ. Furthermore, the NF- $\mathrm{KB}$ pathway plays significant role in the pathogenesis of T2DM and its associated complications [62,63]. Additionally, STAT1 has been predicted by TRRUST (Transcrip- 
tional Regulatory Relationships Unraveled by Sentence-based Text mining) analysis. The involvement of STAT1 is supported by data showing the activation of the IL23/JAK/STAT (Interleukin-23/ Janus Kinase/Signal Transducer and Activator of Transcription) pathway in T2DM PBMCs [64] and the activation of STAT1 in SCZ, which negatively correlated with cognitive performance [65].

On the other hand, the ERG transcription factor [66] was identified as implicated in the regulation of the downregulated DEGs in both SCZ and T2DM. ERG has been found to be required for hematopoiesis, hematopoietic stem-cell function, and the maintenance of normal platelet numbers [67], and it acts as an oncogene in leukemias, as well as solid tumors, such as prostate cancer [68]. This is the first report associating ERG with either SCZ or T2DM, and further studies need to be carried out for the evaluation of the role of this transcription factor in the etiopathogenesis of these disorders.

Interestingly, our network analysis identified TGF (Transforming Growth Factor)- $\beta$ to be implicated in both SCZ and T2DM. This is worth noting as SCZ and T2DM have been associated with activated peripheral and central inflammatory responses $[69,70]$. As previously reported, despite the presence of increased serum levels of TGF- $\beta$ in SCZ [71] and T2DM patients [72], no significant modulation or, more strikingly, a downregulation in the expression of this cytokine can be observed in PBMCs [73,74]. Along the same lines, in our study, the expression levels of TGF- $\beta$ were not found to be significantly modulated in either of the two disorders (with only a trend of reduction-FDR $=0.068$ for T2DM and $\mathrm{FDR}=0.346$ for SCZ). However, TGF- $\beta$ resulted a central hub in the functional network constructed using the common DEGs between SCZ and T2DM. In particular, TGF- $\beta$ was found to functionally interact with 17 out of the 47 genes belonging to the network (i.e., PACS2, APRT, BCR, BTG2, DGKZ, ELF4, FCHO1, FLNA, IDUA, JUNB, MFSD10, MYO1G, PCSK7, PFN1, RALY, SLA2, and SLC10A3). Notably, among the TGF- $\beta$-interacting genes, BTG2 (B-cell translocation gene 2), which interacts with the bone morphogenetic protein (BMP)-activated SMADs (Small Mother Against Decapentaplegic) [75], known to antagonize the effect of TGF- $\beta$, resulted commonly upregulated in our analysis. We may speculate that alteration in the SMAD-dependent signaling pathways could be partly responsible for either the onset or the progression of SCZ and T2DM and, hence, warrants further exploration. We are currently not able to determine whether the common transcriptomic signature that we herein characterized represents the consequence of the diseases or rather an ab initio genetic susceptibility factor that may promote the comorbidity of T2DM in SCZ patients. Functional studies on the role of the identified biological processes will be needed to dismantle their etiopathogenetic role and to exploit them for better pharmacological management of SCZ patients.

There are several limitations in the present study that need to be mentioned. The analysis was performed on PBMCs, which do not represent the main tissue of action for T2DM or SCZ. Therefore, further work should be done in order to identify common transcriptional changes affecting the pancreas and the central nervous system of both SCZ and T2DM patients. Moreover, our study involved a limited number of samples; hence, no adjustment for sex, age, and disease duration could be performed. Moreover, we have no data about whether a set of patients included in the analysis suffered from both diseases at the same time. Lastly, the datasets only shared 11,112 genes, and we could not determine whether the remaining genes were modulated in the two disorders.

\section{Conclusions}

This study aimed to provide novel molecular signatures and pathways that may underlie both SCZ and T2DM pathogenesis. Using a comprehensive systems biology analysis, we determined the molecular signatures and pathways via the reconstruction of comprehensive SCZ and T2DM specific biological networks. We revealed 28 genes concordantly dysregulated in SCZ and T2DM that may clarify genes that potentially promote the progression of T2DM in SCZ patients. Our study predicted STAT1, RELA, NFKB1, and ERG has regulators of the common DEGs between SCZ and T2DM. Immune 
systems, inflammatory-associated processes, and membrane trafficking pathways were prioritized as common biological processes in SCZ and T2DM. The new common genes and associated regulators, as well as biological processes, identified in this study can be a crucial resource for understanding the association between SCZ and T2DM and may help to develop a precision medicine approach.

Supplementary Materials: The following are available online at https://www.mdpi.com/2073-4 425/12/2/237/s1: Figure S1. Network of enriched Gene Ontology terms; Table S1. List of the differentially expressed genes (DEGs) identified in SCZ PBMCs by meta-analysis of the GSE18312 and GSE27383 datasets; Table S2. List of the differentially expressed genes (DEGs) identified in T2DM PBMCs by analysis of the GSE9006 dataset; Table S3. Predicted transcription factors regulating the differentially expressed genes (DEGs) in SCZ and T2DM PBMCs, using the TRRUST database.

Author Contributions: Conceptualization, M.R.R., F.N., R.C. and P.F.; data curation, M.R.R., T.I., M.C.P., R.C., F.F., A.B., T.Y.D., E.G. and M.R.I.; formal analysis, M.R.R., T.I., M.C.P., M.P. and T.Y.D.; funding acquisition, F.N.; investigation, A.B. and M.R.R.; methodology, M.R.R., T.I., F.N., M.C.P., T.Y.D., E.G., M.R.I., B.M.M. and P.F.; supervision, F.N.; validation, R.C., M.A.M. and P.F.; visualization, M.C.P.; writing-original draft, M.R.R., F.F., and A.B.; writing-review and editing, F.N., R.C., M.P., B.M.M. and P.F. All authors have read and agreed to the published version of the manuscript.

Funding: This study was supported by current research funds 2020 of IRCCS “Centro Neurolesi Bonino-Pulejo", Messina, Italy.

Institutional Review Board Statement: Not applicable.

Informed Consent Statement: Not applicable.

Data Availability Statement: All data are available in the Gene Expression Omnibus (GEO) database (https://www.ncbi.nlm.nih.gov/gds).

Conflicts of Interest: The authors declare no conflict of interest.

\section{References}

1. Rouillon, F.; Sorbara, F. Schizophrenia and diabetes: Epidemiological data. Eur. Psychiatry 2005, 20, S345-S348. [CrossRef]

2. Lin, P.I.; Shuldiner, A.R. Rethinking the genetic basis for comorbidity of schizophrenia and type 2 diabetes. Schizophr. Res. 2010, 123, 234-243. [CrossRef]

3. Suvisaari, J.; Keinänen, J.; Eskelinen, S.; Mantere, O. Diabetes and schizophrenia. Curr. Diabetes Rep. 2016, 16, 16. [CrossRef]

4. Holt, R.I.G.; Mitchell, A.J. Diabetes mellitus and severe mental illness: Mechanisms and clinical implications. Nat. Rev. Endocrinol. 2015, 11, 79-89. [CrossRef]

5. Young, S.L.; Taylor, M.; Lawrie, S.M. "First do no harm." A systematic review of the prevalence and management of antipsychotic adverse effects. J. Psychopharmacol. 2015, 29, 353-362. [CrossRef]

6. Vancampfort, D.; Correll, C.U.; Galling, B.; Probst, M.; De Hert, M.; Ward, P.B.; Rosenbaum, S.; Gaughran, F.; Lally, J.; Stubbs, B. Diabetes mellitus in people with schizophrenia, bipolar disorder and major depressive disorder: A systematic review and large scale meta-analysis. World Psychiatry 2016, 15, 166-174. [CrossRef] [PubMed]

7. Correll, C.U.; Detraux, J.; De Lepeleire, J.; De Hert, M. Effects of antipsychotics, antidepressants and mood stabilizers on risk for physical diseases in people with schizophrenia, depression and bipolar disorder. World Psychiatry 2015, 14, 119-136. [CrossRef] [PubMed]

8. Smith, M.; Hopkins, D.; Peveler, R.C.; Holt, R.I.G.; Woodward, M.; Ismail, K. First-v. second-generation antipsychotics and risk for diabetes in schizophrenia: Systematic review and meta-analysis. Br. J. Psychiatry 2008, 192, 406-411. [CrossRef] [PubMed]

9. Hackinger, S.; Prins, B.; Mamakou, V.; Zengini, E.; Marouli, E.; Brčić, L.; Serafetinidis, I.; Lamnissou, K.; Kontaxakis, V.; Dedoussis, G. Evidence for genetic contribution to the increased risk of type 2 diabetes in schizophrenia. Transl. Psychiatry 2018, 8, 1-10. [CrossRef]

10. Purcell, S.M.; Wray, N.R.; Stone, J.L.; Visscher, P.M. Common polygenic variation contributes to risk of schizophrenia and bipolar disorder. Nature 2009, 460, 748-752.

11. Stringer, S.; Kahn, R.S.; de Witte, L.D.; Ophoff, R.A.; Derks, E.M. Genetic liability for schizophrenia predicts risk of immune disorders. Schizophr. Res. 2014, 159, 347-352. [CrossRef]

12. Padmanabhan, J.L.; Nanda, P.; Tandon, N.; Mothi, S.S.; Bolo, N.; McCarroll, S.; Clementz, B.A.; Gershon, E.S.; Pearlson, G.D.; Sweeney, J.A.; et al. Polygenic risk for type 2 diabetes mellitus among individuals with psychosis and their relatives. J. Psychiatr. Res. 2016, 77, 52-58. [CrossRef] [PubMed] 
13. Rahman, M.R.; Islam, T.; Turanli, B.; Zaman, T.; Faruquee, H.M.; Rahman, M.M.; Mollah, M.N.H.; Nanda, R.K.; Arga, K.Y.; Gov, E.; et al. Network-based approach to identify molecular signatures and therapeutic agents in Alzheimer's disease. Comput. Biol. Chem. 2019, 78, 431-439. [CrossRef]

14. Rahman, M.R.; Islam, T.; Zaman, T.; Shahjaman, M.; Karim, M.R.; Huq, F.; Quinn, J.M.W.; Holsinger, R.M.D.; Gov, E.; Moni, M.A. Identification of molecular signatures and pathways to identify novel therapeutic targets in Alzheimer's disease: Insights from a systems biomedicine perspective. Genomics 2020, 112, 1290-1299. [CrossRef] [PubMed]

15. Ma, C.; Gu, C.; Huo, Y.; Li, X.; Luo, X.-J. The integrated landscape of causal genes and pathways in schizophrenia. Transl. Psychiatry 2018, 8, 1-14. [CrossRef] [PubMed]

16. Wang, Z.; Li, P.; Wu, T.; Zhu, S.; Deng, L.; Cui, G. Axon guidance pathway genes are associated with schizophrenia risk. Exp. Ther. Med. 2018, 16, 4519-4526. [CrossRef]

17. Petralia, M.C.; Ciurleo, R.; Saraceno, A.; Pennisi, M.; Basile, M.S.; Fagone, P.; Bramanti, P.; Nicoletti, F.; Cavalli, E. Meta-Analysis of Transcriptomic Data of Dorsolateral Prefrontal Cortex and of Peripheral Blood Mononuclear Cells Identifies Altered Pathways in Schizophrenia. Genes 2020, 11, 390. [CrossRef]

18. Ding, L.; Fan, L.; Xu, X.; Fu, J.; Xue, Y. Identification of core genes and pathways in type 2 diabetes mellitus by bioinformatics analysis. Mol. Med. Rep. 2019, 20, 2597-2608. [CrossRef]

19. Zhong, M.; Wu, Y.; Ou, W.; Huang, L.; Yang, L. Identification of key genes involved in type 2 diabetic islet dysfunction: A bioinformatics study. Biosci. Rep. 2019, 39, 39. [CrossRef]

20. Kaizer, E.C.; Glaser, C.L.; Chaussabel, D.; Banchereau, J.; Pascual, V.; White, P.C. Gene expression in peripheral blood mononuclear cells from children with diabetes. J. Clin. Endocrinol. Metab. 2007, 92, 3705-3711. [CrossRef]

21. Gardiner, E.J.; Cairns, M.J.; Liu, B.; Beveridge, N.J.; Carr, V.; Kelly, B.; Scott, R.J.; Tooney, P.A. Gene expression analysis reveals schizophrenia-associated dysregulation of immune pathways in peripheral blood mononuclear cells. J. Psychiatr. Res. 2013, 47, 425-437. [CrossRef]

22. Bousman, C.A.; Chana, G.; Glatt, S.J.; Chandler, S.D.; May, T.; Lohr, J.; Kremen, W.S.; Tsuang, M.T.; Everall, I.P. Positive symptoms of psychosis correlate with expression of ubiquitin proteasome genes in peripheral blood. Am. J. Med. Genet. Part B Neuropsychiatr. Genet. 2010, 153B, 1336-1341. [CrossRef]

23. Bousman, C.A.; Chana, G.; Glatt, S.J.; Chandler, S.D.; Lucero, G.R.; Tatro, E.; May, T.; Lohr, J.B.; Kremen, W.S.; Tsuang, M.T.; et al. Preliminary evidence of ubiquitin proteasome system dysregulation in schizophrenia and bipolar disorder: Convergent pathway analysis findings from two independent samples. Am. J. Med. Genet. B Neuropsychiatr. Genet. 2010, 153B, 494-502. [CrossRef] [PubMed]

24. van Beveren, N.J.M.; Buitendijk, G.H.S.; Swagemakers, S.; Krab, L.C.; Röder, C.; de Haan, L.; van der Spek, P.; Elgersma, Y. Marked reduction of AKT1 expression and deregulation of AKT1-associated pathways in peripheral blood mononuclear cells of schizophrenia patients. PLoS ONE 2012, 7, e32618. [CrossRef] [PubMed]

25. Toro-Domínguez, D.; Martorell-Marugán, J.; López-Domínguez, R.; García-Moreno, A.; González-Rumayor, V.; Alarcón-Riquelme, M.E.; Carmona-Sáez, P. ImaGEO: Integrative gene expression meta-analysis from GEO database. Bioinformatics 2019, 35, 880-882. [CrossRef] [PubMed]

26. Rau, A.; Gallopin, M.; Celeux, G.; Jaffrézic, F. Data-based filtering for replicated high-throughput transcriptome sequencing experiments. Bioinformatics 2013, 29, 2146-2152. [CrossRef] [PubMed]

27. Ritchie, M.E.; Phipson, B.; Wu, D.; Hu, Y.; Law, C.W.; Shi, W.; Smyth, G.K. Limma powers differential expression analyses for RNA-sequencing and microarray studies. Nucleic Acids Res. 2015, 43, e47. [CrossRef] [PubMed]

28. Zhou, G.; Soufan, O.; Ewald, J.; Hancock, R.E.W.; Basu, N.; Xia, J. Network Analyst 3.0: A visual analytics platform for comprehensive gene expression profiling and meta-analysis. Nucleic Acids Res. 2019, 47, W234-W241. [CrossRef]

29. Konishi, S. Normalizing and variance stabilizing transformations for intraclass correlations. Ann. Inst. Stat. Math. 1985, 37, 87-94. [CrossRef]

30. Hansen, K.D.; Irizarry, R.A.; Wu, Z. Removing technical variability in RNA-seq data using conditional quantile normalization. Biostatistics 2012, 13, 204-216. [CrossRef]

31. Kalinka, A.T. The probability of drawing intersections: Extending the hypergeometric distribution. arXiv 2013, arXiv:1305.0717.

32. Zhou, Y.; Zhou, B.; Pache, L.; Chang, M.; Khodabakhshi, A.H.; Tanaseichuk, O.; Benner, C.; Chanda, S.K. Metascape provides a biologist-oriented resource for the analysis of systems-level datasets. Nat. Commun. 2019, 10, 1523. [CrossRef] [PubMed]

33. Zuberi, K.; Franz, M.; Rodriguez, H.; Montojo, J.; Lopes, C.T.; Bader, G.D.; Morris, Q. GeneMANIA Prediction Server 2013 Update. Nucleic Acids Res. 2013, 41, W115-W122. [CrossRef] [PubMed]

34. Reimand, J.; Isserlin, R.; Voisin, V.; Kucera, M.; Tannus-Lopes, C.; Rostamianfar, A.; Wadi, L.; Meyer, M.; Wong, J.; Xu, C.; et al. Pathway enrichment analysis and visualization of omics data using g:Profiler, GSEA, Cytoscape and EnrichmentMap. Nat. Protoc. 2019, 14, 482-517. [CrossRef] [PubMed]

35. Fagone, P.; Mazzon, E.; Cavalli, E.; Bramanti, A.; Petralia, M.C.; Mangano, K.; Al-Abed, Y.; Bramati, P.; Nicoletti, F. Contribution of the macrophage migration inhibitory factor superfamily of cytokines in the pathogenesis of preclinical and human multiple sclerosis: In silico and in vivo evidences. J. Neuroimmunol. 2018, 322, 46-56. [CrossRef]

36. Fagone, P.; Patti, F.; Mangano, K.; Mammana, S.; Coco, M.; Touil-Boukoffa, C.; Chikovani, T.; Di Marco, R.; Nicoletti, F. Heme oxygenase-1 expression in peripheral blood mononuclear cells correlates with disease activity in multiple sclerosis. J. Neuroimmunol. 2013, 261, 82-86. [CrossRef] 
37. Cavalli, E.; Mazzon, E.; Mammana, S.; Basile, M.S.; Lombardo, S.D.; Mangano, K.; Bramanti, P.; Nicoletti, F.; Fagone, P.; Petralia, M.C. Overexpression of Macrophage Migration Inhibitory Factor and Its Homologue D-Dopachrome Tautomerase as Negative Prognostic Factor in Neuroblastoma. Brain Sci. 2019, 9, 284. [CrossRef]

38. Rahman, M.R.; Petralia, M.C.; Ciurleo, R.; Bramanti, A.; Fagone, P.; Shahjaman, M.; Wu, L.; Sun, Y.; Turanli, B.; Arga, K.Y.; et al. Comprehensive analysis of RNA-seq gene expression profiling of brain transcriptomes reveals novel genes, regulators, and pathways in autism spectrum disorder. Brain Sci. 2020, 10, 747. [CrossRef]

39. Fagone, P.; Mangano, K.; Pesce, A.; Portale, T.R.; Puleo, S.; Nicoletti, F. Emerging therapeutic targets for the treatment of hepatic fibrosis. Drug Discov. Today 2016, 21, 369-375. [CrossRef]

40. Günther, S.; Fagone, P.; Jalce, G.; Atanasov, A.G.; Guignabert, C.; Nicoletti, F. Role of MIF and D-DT in immune-inflammatory, autoimmune, and chronic respiratory diseases: From pathogenic factors to therapeutic targets. Drug Discov. Today 2019, 24, 428-439. [CrossRef] [PubMed]

41. Donia, M.; Andersen, R.; Kjeldsen, J.W.; Fagone, P.; Munir, S.; Nicoletti, F.; Andersen, M.H.; Straten, P.T.; Svane, I.M. Aberrant expression of MHC class II in melanoma attracts inflammatory tumor-specific CD4 ${ }^{+} \mathrm{T}$-cells, which dampen CD8 ${ }^{+} \mathrm{T}$-cell antitumor reactivity. Cancer Res. 2015, 75, 3747-3759. [CrossRef] [PubMed]

42. Rothweiler, F.; Michaelis, M.; Brauer, P.; Otte, J.; Weber, K.; Fehse, B.; Doerr, H.W.; Wiese, M.; Kreuter, J.; Al-Abed, Y.; et al. Anticancer effects of the nitric oxide-modified saquinavir derivative saquinavir-NO against multidrug-resistant cancer cells. Neoplasia 2010, 12, 1023-1030. [CrossRef] [PubMed]

43. Steelman, L.S.; Martelli, A.M.; Cocco, L.; Libra, M.; Nicoletti, F.; Abrams, S.L.; McCubrey, J.A. The therapeutic potential of mTOR inhibitors in breast cancer. Br. J. Clin. Pharmacol. 2016, 82, 1189-1212. [CrossRef] [PubMed]

44. Maksimovic-Ivanic, D.; Fagone, P.; McCubrey, J.; Bendtzen, K.; Mijatovic, S.; Nicoletti, F. HIV-protease inhibitors for the treatment of cancer: Repositioning HIV protease inhibitors while developing more potent NO-hybridized derivatives? Int. J. Cancer 2017, 140, 1713-1726. [CrossRef]

45. Mangano, K.; Cavalli, E.; Mammana, S.; Basile, M.S.; Caltabiano, R.; Pesce, A.; Puleo, S.; Atanasov, A.G.; Magro, G.; Nicoletti, F.; et al. Involvement of the $\mathrm{Nrf2} / \mathrm{HO}-1 / \mathrm{CO}$ axis and therapeutic intervention with the CO-releasing molecule CORM-A1, in a murine model of autoimmune hepatitis. J. Cell. Physiol. 2018, 233, 4156-4165. [CrossRef] [PubMed]

46. Schwartsburd, P.M. Catabolic and anabolic faces of insulin resistance and their disorders: A new insight into circadian control of metabolic disorders leading to diabetes. Future Sci. OA 2017, 3, FSO201. [CrossRef]

47. Yarwood, R.; Hellicar, J.; Woodman, P.G.; Lowe, M. Membrane trafficking in health and disease. Dis. Model. Mech. 2020, 13, dmm043448. [CrossRef]

48. Schubert, K.O.; Föcking, M.; Prehn, J.H.M.; Cotter, D.R. Hypothesis review: Are clathrin-mediated endocytosis and clathrindependent membrane and protein trafficking core pathophysiological processes in schizophrenia and bipolar disorder? Mol. Psychiatry 2012, 17, 669-681. [CrossRef]

49. Wang, X.; Christian, K.M.; Song, H.; Ming, G. Synaptic dysfunction in complex psychiatric disorders: From genetics to mechanisms. Genome Med. 2018, 10, 9. [CrossRef]

50. Van Kesteren, C.; Gremmels, H.; De Witte, L.D.; Hol, E.M.; Van Gool, A.R.; Falkai, P.G.; Kahn, R.S.; Sommer, I.E.C. Immune involvement in the pathogenesis of schizophrenia: A meta-analysis on postmortem brain studies. Transl. Psychiatry 2017, 7, e1075. [CrossRef]

51. Zhou, T.; Hu, Z.; Yang, S.; Sun, L.; Yu, Z.; Wang, G. Role of adaptive and innate immunity in type 2 diabetes mellitus. J. Diabetes Res. 2018, 2018, 1-9. [CrossRef]

52. Chase, K.A.; Cone, J.J.; Rosen, C.; Sharma, R.P. The value of interleukin 6 as a peripheral diagnostic marker in schizophrenia. BMC Psychiatry 2016, 16, 1-7. [CrossRef]

53. Pouget, J.G.; Han, B.; Wu, Y.; Mignot, E.; Ollila, H.M.; Barker, J.; Spain, S.; Dand, N.; Trembath, R.; Martin, J.; et al. Cross-disorder analysis of schizophrenia and 19 immune-mediated diseases identifies shared genetic risk. Hum. Mol. Genet. 2019, 28, 3498-3513. [CrossRef]

54. Ballak, D.B.; Stienstra, R.; Tack, C.J.; Dinarello, C.A.; van Diepen, J.A. IL-1 family members in the pathogenesis and treatment of metabolic disease: Focus on adipose tissue inflammation and insulin resistance. Cytokine 2015, 75, 280-290. [CrossRef]

55. Spranger, J.; Kroke, A.; Möhlig, M.; Hoffmann, K.; Bergmann, M.M.; Ristow, M.; Boeing, H.; Pfeiffer, A.F.H. Inflammatory cytokines and the risk to develop type 2 diabetes: Results of the prospective population-based European Prospective Investigation into Cancer and Nutrition (EPIC)-Potsdam study. Diabetes 2003, 52, 812-817. [CrossRef] [PubMed]

56. Stienstra, R.; Joosten, L.A.B.; Koenen, T.; Van Tits, B.; Van Diepen, J.A.; Van Den Berg, S.A.A.; Rensen, P.C.N.; Voshol, P.J.; Fantuzzi, G.; Hijmans, A.; et al. The inflammasome-mediated caspase-1 activation controls adipocyte differentiation and insulin sensitivity. Cell Metab. 2010, 12, 593-605. [CrossRef] [PubMed]

57. Ruscitti, P.; Masedu, F.; Alvaro, S.; Airò, P.; Battafarano, N.; Cantarini, L.; Cantatore, F.P.; Carlino, G.; D'Abrosca, V.; Frassi, M.; et al. Anti-interleukin-1 treatment in patients with rheumatoid arthritis and type 2 diabetes (TRACK): A multicentre, open-label, randomised controlled trial. PLoS Med. 2019, 16, e1002901. [CrossRef]

58. Jiang, J.; Peng, C.; Sun, L.; Li, J.; Qing, Y.; Hu, X.; Yang, X.; Li, Y.; Xu, C.; Zhang, J.; et al. Leukocyte Proteomic Profiling in First-Episode Schizophrenia Patients: Does Oxidative Stress Play Central Roles in the Pathophysiology Network of Schizophrenia? Antioxid. Redox Signal. 2019, 31, 579-588. [CrossRef] [PubMed] 
59. Arya, A.K.; Pokharia, D.; Tripathi, K. Relationship between oxidative stress and apoptotic markers in lymphocytes of diabetic patients with chronic non healing wound. Diabetes Res. Clin. Pract. 2011, 94, 377-384. [CrossRef]

60. Hashimoto, R.; Ohi, K.; Yasuda, Y.; Fukumoto, M.; Yamamori, H.; Takahashi, H.; Iwase, M.; Okochi, T.; Kazui, H.; Saitoh, O. Variants of the RELA gene are associated with schizophrenia and their startle responses. Neuropsychopharmacology 2011, 36, 1921-1931. [CrossRef]

61. Song, X.-Q.; Lv, L.-X.; Li, W.-Q.; Hao, Y.-H.; Zhao, J.-P. The interaction of nuclear factor-kappa B and cytokines is associated with schizophrenia. Biol. Psychiatry 2009, 65, 481-488. [CrossRef]

62. Volk, D.W.; Moroco, A.E.; Roman, K.M.; Edelson, J.R.; Lewis, D.A. The role of the nuclear factor- $\mathrm{kB}$ transcriptional complex in cortical immune activation in schizophrenia. Biol. Psychiatry 2019, 85, 25-34. [CrossRef]

63. Patel, S.; Santani, D. Role of NF-kB in the pathogenesis of diabetes and its associated complications. Pharmacol. Rep. 2009, 61, 595-603. [CrossRef]

64. Rezaeepoor, M.; Hoseini-Aghdam, M.; Sheikh, V.; Eftekharian, M.M.; Behzad, M. Evaluation of interleukin-23 and JAKs /STATs/SOCSs/ROR-ct expression in type 2 diabetes mellitus patients treated with or without sitagliptin. J. Interf. Cytokine Res. 2020, 40, 515-523. [CrossRef]

65. Sharma, R.P.; Rosen, C.; Melbourne, J.K.; Feiner, B.; Chase, K.A. Activated phosphorylated STAT1 levels as a biologically relevant immune signal in schizophrenia. Neuroimmunomodulation 2017, 23, 224-229. [CrossRef] [PubMed]

66. Rao, V.N.; Papas, T.S.; Reddy, E.S.P. Erg, a human ets-related gene on chromosome 21:Aternative splicing, polyadenylation, and translation. Science 1987, 237, 635-639. [CrossRef] [PubMed]

67. Loughran, S.J.; Kruse, E.A.; Hacking, D.F.; de Graaf, C.A.; Hyland, C.D.; Willson, T.A.; Henley, K.J.; Ellis, S.; Voss, A.K.; Metcalf, D.; et al. The transcription factor Erg is essential for definitive hematopoiesis and the function of adult hematopoietic stem cells. Nat. Immunol. 2008, 9, 810-819. [CrossRef]

68. Yi, H.K.; Fujimura, Y.; Ouchida, M.; Prasad, D.D.K.; Rao, V.N.; Reddy, E.S.P. Inhibition of apoptosis by normal and aberrant Fli-1 and erg proteins involved in human solid tumors and leukemias. Oncogene 1997, 14, 1259-1268. [CrossRef] [PubMed]

69. Meyer, U.; Schwarz, M.J.; Müller, N. Inflammatory processes in schizophrenia: A promising neuroimmunological target for the treatment of negative/cognitive symptoms and beyond. Pharmacol. Ther. 2011, 132, 96-110. [CrossRef]

70. Tsalamandris, S.; Antonopoulos, A.S.; Oikonomou, E.; Papamikroulis, G.A.; Vogiatzi, G.; Papaioannou, S.; Deftereos, S.; Tousoulis, D. The role of inflammation in diabetes: Current concepts and future perspectives. Eur. Cardiol. Rev. 2019, 14, 50-59. [CrossRef] [PubMed]

71. Miller, B.J.; Buckley, P.; Seabolt, W.; Mellor, A.; Kirkpatrick, B. Meta-analysis of cytokine alterations in schizophrenia: Clinical status and antipsychotic effects. Biol. Psychiatry 2011, 70, 663-671. [CrossRef] [PubMed]

72. Qiao, Y.C.; Chen, Y.L.; Pan, Y.H.; Ling, W.; Tian, F.; Zhang, X.X.; Zhao, H.L. Changes of transforming growth factor beta 1 in patients with type 2 diabetes and diabetic nephropathy. Medicine (Baltimore) 2017, 96, e6583. [CrossRef]

73. Abbasi, F.; Amiri, P.; Sayahpour, F.A.; Pirmoradi, S.; Abolhalaj, M.; Larijani, B.; Bazzaz, J.T.; Amoli, M.M. TGF- $\beta$ and IL-23 gene expression in unstimulated PBMCs of patients with diabetes. Endocrine 2012, 41, 430-434. [CrossRef] [PubMed]

74. Finardi, A.; Brambilla, P.; Furlan, R. Immune signature in PBMCs of patients with bipolar disorder and schizophrenia. Neurol. Psychiatry Brain Res. 2016, 22, 11. [CrossRef]

75. Park, S.; Lee, Y.J.; Lee, H.-J.; Seki, T.; Hong, K.-H.; Park, J.; Beppu, H.; Lim, I.K.; Yoon, J.-W.; Li, E.; et al. B-Cell Translocation Gene 2 (Btg2) Regulates Vertebral Patterning by Modulating Bone Morphogenetic Protein/Smad Signaling. Mol. Cell. Biol. 2004, 24, 10256-10262. [CrossRef] 